\title{
Performance analysis of an active diffuser in mixing ventilation for cell office by using numerical approach
}

\author{
Mehrdad Rabani ${ }^{1,2 *}$, Habtamu B. Madessa ${ }^{1}$, Natasa Nord $^{2}$, and Peter Schild ${ }^{1}$ \\ ${ }^{1}$ Department of Civil Engineering and Energy Technology, Oslo Metropolitan University, Norway \\ ${ }^{2}$ Department of Energy and Process Engineering, Norwegian University of Science and Technology, Norway
}

\begin{abstract}
Energy efficiency in buildings is nowadays considered as an essential step to reduce $\mathrm{CO}_{2}$ emissions and energy utilization. At the same time, new technologies such as building space heating using active air heating has simplified the heating system without any need for backup heating system. This study investigated the thermal stratification of mixing ventilation system equipped with a radial active supply diffuser for space heating of an office room designed according to the Norwegian passive house standard by using Star-CCM+. Simulations were performed for different supply airflow rates with corresponding slot openings of the active diffuser at different outdoor conditions for winter season. The combined effect of the supply airflow rate and the outdoor air temperature were also described in the form of Archimedes number $(A r)$. The results showed that adopting active diffuser could avoid the temperature stratification for all the simulated cases by preserving the throw length of supply jet. In addition, the lowest temperature effectiveness of $38 \%$ occurred when a high supply temperature was used in the coldest day. Furthermore, with the supply temperature $24{ }^{\circ} \mathrm{C}$, the airflow rate $49.41 / \mathrm{s}$ at the outdoor temperature $-15{ }^{\circ} \mathrm{C}$ would result in a favorable average of $P M V \sim 0.497$.
\end{abstract}

\section{Introduction}

A large portion of the energy use in Europe is connected to the building sectors. The relation between the $\mathrm{CO}_{2}$ emission and the energy use is an incentive to adopt more efficient retrofit interventions in buildings, thereby reducing the total energy need [1]. It is also important that acceptable indoor air quality (IAQ) should be always maintained by means of building service systems while considering the primary requirements of buildings with focus on substantial reduction in building energy use in the building retrofitting process.

As a common practice in reducing the building energy use, upgrade of building envelope, has shown a great potential towards a building with low energy use, as suggested by the passive house concept [2]. Since the energy need for heating in such buildings is very low, for example $20 \mathrm{kWh} / \mathrm{m}^{2}$.year for passive office buildings in Oslo, Norway, adopting a cost effective system that can fulfil both heating and ventilation requirements is reasonable.

In one attempt in the 70 's, a simple room heating was tested using supply air at ceiling level with overheated temperature, so-called all-air heating. The purpose was to avoid local space heating installations by removing the radiators. Unfortunately, the result was a significant degree of temperature stratification, poor IAQ in the occupied zone since the maximum heating demand was 5-10 times higher than the upcoming building regulations on passive house level [3].
Other studies also investigated the all-air heating system experimentally and numerically, however the problems such as high vertical temperature gradient [4], stationary region of airflow in the occupancy zone [5], and non-uniform velocity and temperature distributions [6] were the reported negative issues.

This paper dealt with simulation of all-air heating of a cell office by means an active supply diffuser. The variable slot opening in this device allowed the adjustment of the airflow rate by changing the position of moving plates leading to a constant supply air velocity at whole range of operational airflow rate. Therefore, the main aim was to address the following question: is it possible to improve the performance of the all-air heating system in terms of thermal comfort and temperature stratification by adopting an active supply diffuser in a cell office for the coldest days in Oslo?

\section{Method}

\subsection{Cell office model and boundary conditions}

The analyzed cell office, shown in Fig. 1, was located in Oslo, and constructed based on the Norwegian passive house standard [7]. The room had the dimensions $4.2 \mathrm{~m} \times$ $2.25 \mathrm{~m} \times 2.7 \mathrm{~m}$. Window dimensions were $1.7 \mathrm{~m} \times 2 \mathrm{~m}$. A seated occupant was modelled using a cylindrical dummy with $1.1 \mathrm{~m}$ height and $0.6 \mathrm{~m}$ diameter. Furthermore, there were a PC, a table and, a lighting

\footnotetext{
*Corresponding author: Mehrdad Rabani@,oslomet.no
} 
fixture modelled using the rectangular cubes with dimensions of $0.3 \mathrm{~m} \times 0.3 \mathrm{~m} \times 0.4 \mathrm{~m}, 2 \mathrm{~m} \times 0.8 \mathrm{~m} \times 0.02 \mathrm{~m}$, and $1.2 \mathrm{~m} \times 0.18 \mathrm{~m} \times 0.04 \mathrm{~m}$ respectively.

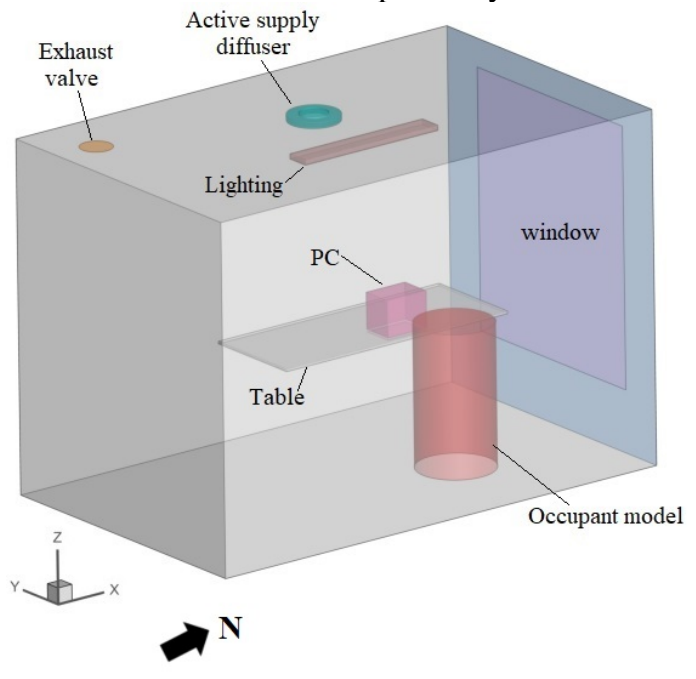

Fig. 1. Simulated office cell

The all-air heating ventilation system was simulated with regard to the experimental setup [7]. Therefore, the radial supply diffuser placed on the ceiling was modelled. The diffuser was a TTC-250-active supply diffuser comprised of several moving plates used to vary airflow rate while maintaining the supply velocity constant, thereby providing a draught-free performance for different ranges of airflow rates (Fig. 2) [8].

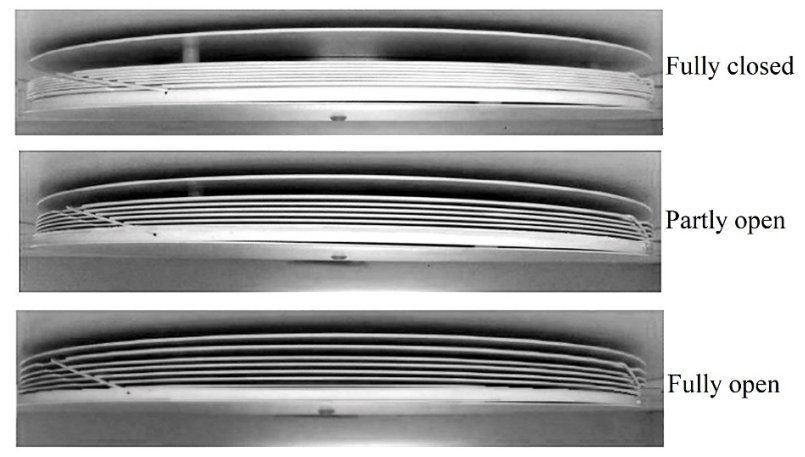

Fig. 2. Adjustment of slot openings in the active supply diffuser

For the boundary condition, the inlet of the active supply diffuser was modelled using the velocity inlet with uniform velocity. It should be noted that since the inlet was considered on ceiling, the inlet velocity was modified for different airflow rates in order to have a constant supply velocity at the outlet of slot openings. The airflow rate amounts and the corresponding slot opening were adjusted so that a constant air velocity was achieved in all cases. It should be noted that the airflow rates were selected always higher than the minimum requirements for the non-residential Norwegian passive buildings [2]. The exhaust was modelled using pressure outlet boundary condition with zero gauge pressure. The dummy, the PC, and the lighting were simulated using heat source boundary condition with the values of 120 $\mathrm{W}, 30 \mathrm{~W}$, and $136 \mathrm{~W}$ respectively [7]. The table was modelled using adiabatic boundary condition. The floor was modelled using adiabatic boundary condition, All the walls and ceiling were simulated using "Environmental" boundary condition, which models the convection, conduction and radiation heat transfer through the wall [9]. The overall heat transfer coefficients (U-values) $0.14 \mathrm{~W} / \mathrm{m}^{2} . \mathrm{K}$ for external side wall, $0.25 \mathrm{~W} / \mathrm{m}^{2} . \mathrm{K}$ for internal walls, $0.78 \mathrm{~W} / \mathrm{m}^{2} . \mathrm{K}$ for the window, and $0.10 \mathrm{~W} / \mathrm{m}^{2} . \mathrm{K}$ for the roof were used in simulations. The effect of heat loss due to infiltration was also included in the calculations and was uniformly distributed on the envelope surface. The emissivity of 1 was considered for all the walls [10] and the emissivity of 0.84 was considered for the window [11].

\subsection{Performance indices}

In order to better analyze the all-air heating system performance, the thermal comfort and air distribution indices such as ventilation effectiveness as well as the air jet parameters (synthetically described by the Archimedes number) were used for interpretation of results.

In this study, the characteristics of supply jet were expressed using the Archimedes number definition [12], as described in Eq. 1.

$$
A r=\frac{g \beta l\left(T_{e}-T_{s}\right)}{u_{0}^{2}}
$$

where $T_{s}$ was the supply air temperature, $T_{e}$ was the exhaust air temperature, $u_{0}$, was the supply air velocity, $l$ was the characteristics length, $g$ is the gravitational acceleration, and $\beta$ was the coefficient of thermal expansion. In this study, since the supply device was an active diffuser, the characteristics length was replaced by the net opening area of the supply $\left(a_{0}\right)$. Additionally, since the active diffuser maintained the supply air velocity constant, the velocity in the denominator of the Eq. (1) was substituted by the supply airflow rate. Therefore, the Eq. (1) took the following form:

$$
A r=\frac{g \beta a_{0}^{\frac{5}{2}}\left(T_{e}-T_{s}\right)}{Q_{s}^{2}}
$$

In this study, the ventilation effectiveness based on temperatures and thermal comfort indices including predicted mean vote (PMV) and predicted percentage of dissatisfied (PPD) were used.

The temperature effectiveness evaluates the temperature gradient in the space and is defined as:

$$
\varepsilon=\frac{T_{s}-T_{e}}{T_{s}-T_{\text {ave.o }}}
$$

where $T_{s}, T_{e}$, and $T_{\text {ave.o }}$ are the supply air temperature, the exhaust air temperature, and average air temperature in the occupancy zone respectively. An efficient ventilation system should generate $\varepsilon>1$ that indicates a low temperature difference between the supply and occupied zone. On the contrary, an undesirable ventilation system generates $\varepsilon<1$ which means that supply temperature could be increased to achieve 
acceptable temperature stratification in the occupied zone [13].

$P M V$ is an index commonly used in thermal comfort analysis that examines the occupant thermal sensation according to seven scale points (from -3 , cold, to 3 , hot) considering six factors the air temperature, the mean radiant temperature, the air velocity, the air humidity, physical activity and clothing isolation level, which is defined as:

$$
P M V=\left(0.303 \times e^{-0.036 M}+0.0208\right) \times L
$$

where $M$ is the metabolic heat generation rate and $L$ is the thermal load on the body [14].

$P P D$ index provides a quantitative prediction of thermal dissatisfaction on the $P M V$ seven scale points and is expressed as [14]:

$$
P P D=100-95 \times e^{-0.03353 \times P M V^{4}-0.2179 \times P M V^{2}}
$$

In order to have a favorable environment for a building with low energy use, the $P P D$ should be less than $10 \%$ associated with $-0.5<P M V<0.5$ [14].

\subsection{Numerical setup}

All the simulations were conducted using the commercial CFD software Star-CCM+, a software package solving partial differential equations by means of finite volume method (FVM). The ReynoldsAveraged Navier-Stokes (RANS) equations were solved along with the energy equation using the segregated solver in steady state condition. The segregated solve employed the SIMPLE pressure-velocity coupling algorithm where the mass conservation constraint on the velocity field was fulfilled by solving a pressurecorrection equation. Furthermore, the impact of buoyancy in the room was predicted using the Boussinesq approximation.

The flow regime was considered fully turbulent. The standard $k-\varepsilon$ turbulence model was selected for all the simulations [15]. In addition, a scalable wall treatment was applied to obtain a decent behavior of temperature and velocity profiles in the near-wall region. The radiation heat transfer in the room was modelled using the surface-to-surface (S2S) behaving the air as transparent to radiation.

Based on the proposed geometry, the corresponding computational domain was obtained by means of polyhedral-shaped mesh (Fig. 3) owing to its higher stability than a comparable tetrahedral mesh. Moreover, fewer polyhedral cells were needed to achieve a specified accuracy than even Cartesian hexahedral cells [9]. The mesh cells were refined near the supply diffuser to ensure that the jet supply characteristics was preserved. Therefore, a mesh grid comprised of elements with closest distance $0.05 \mathrm{~cm}$ to diffuser surfaces up to 7 $\mathrm{cm}$ towards the center of the room was constructed to have a $\mathrm{y}+$ consistently lower than 5 .

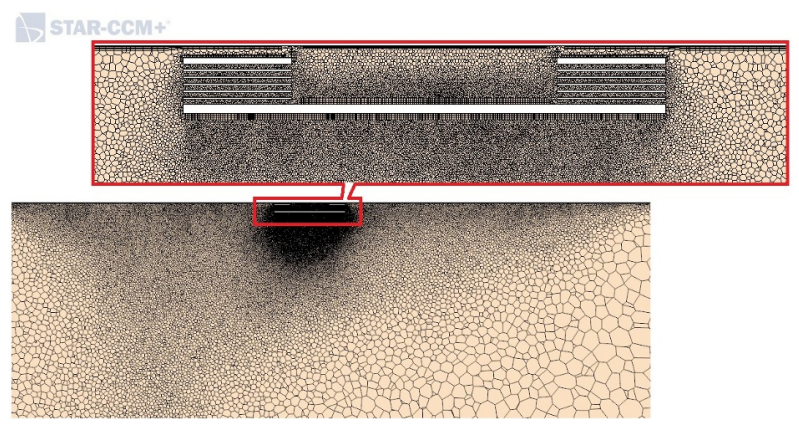

Fig. 3. Mesh generation in Star-CCM+

The steady state condition was achieved by checking the mass imbalance between the supply and the exhaust as well as by monitoring the exhaust temperature. Therefore, the simulations were stopped when the mass imbalance was zero and the outlet temperature became unchanged.

\subsection{Validation of numerical method}

The simulation model was validated by the available experimental data for a cell office of the first building under the passive house standard in Norway [7]. The temperature and velocity obtained from simulations were compared with the experimental data in different heights (at the five points $0.1 \mathrm{~m}, 1.1 \mathrm{~m}, 1.7 \mathrm{~m}, 2.2 \mathrm{~m}$, and $2.5 \mathrm{~m}$ for temperature and three points $0.1 \mathrm{~m}$ (ankle level), $1.1 \mathrm{~m}$ (head level of seated occupant), and $1.7 \mathrm{~m}$ (head level of standing occupant) for the velocity), as shown in Fig. 4.

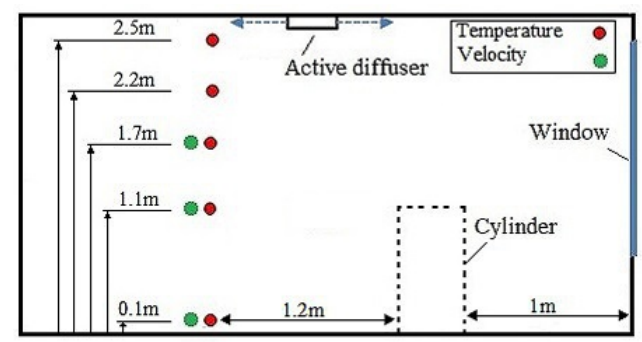

Fig. 4. Location of temperature and velocity measurement points.

Table 1 illustrates the experimental setup used for validation.

Table 1. Experimental parameters used for validation of numerical method

\begin{tabular}{|c|c|}
\cline { 2 - 2 } \multicolumn{1}{c|}{} & Values \\
\hline $\begin{array}{c}\text { Supply airflow rate } \\
(1 / \mathrm{s})\end{array}$ & 49.4 \\
\hline $\begin{array}{c}\text { Supply temperature } \\
\left({ }^{\circ} \mathrm{C}\right)\end{array}$ & 24 \\
\hline $\begin{array}{c}\text { Outside } \\
\text { temperature }\left({ }^{\circ} \mathrm{C}\right)\end{array}$ & -1.8 \\
\hline $\begin{array}{c}\text { Internal heat gains } \\
(\mathrm{W})\end{array}$ & $\begin{array}{c}\text { Occupant: } 120 \\
\text { Lighting: } 136 \\
\text { PC: } 30\end{array}$ \\
\hline
\end{tabular}


The comparison between the experimental data and numerical simulations for the velocity and the temperature variation at measured points was shown in Figs. 5 and 6.

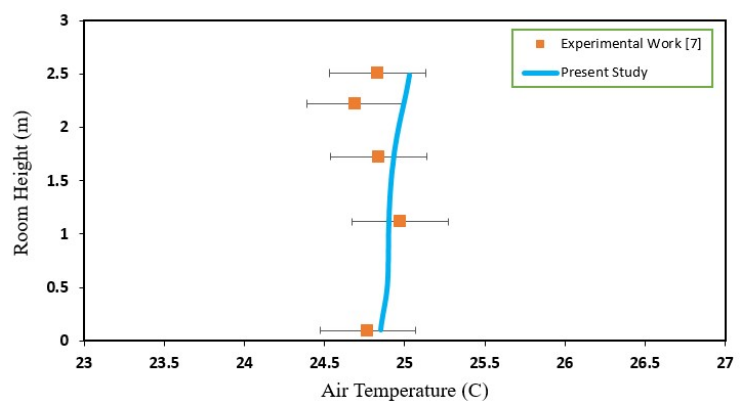

Fig. 5. Vertical air temperature variation at the measurement points

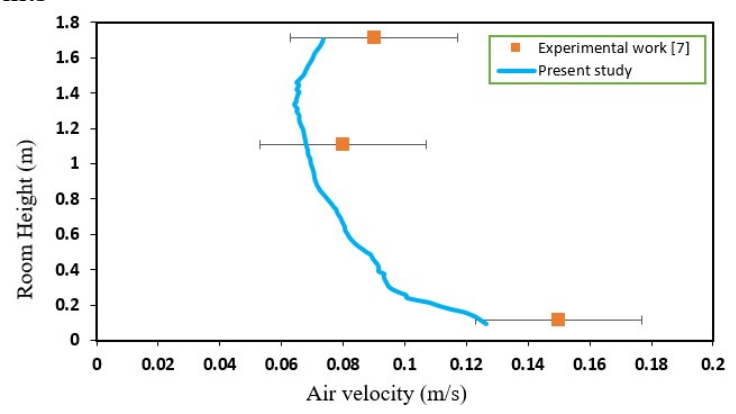

Fig. 6. Vertical air velocity variation at the measurement points

As Figs. 5 and 6 show, both the air velocity and the air temperature variations obtained from simulations were within the uncertainty range of experimental data.

\subsection{Scenarios definition}

Table 2 indicated the eight different evaluated simulation scenarios of the cell office. Each case was a combination of three variables including the outdoor air temperature, the supply air velocity and the supply air temperature representing one specific Archimedes number. It should be mentioned that the positive and negative Archimedes numbers in Table 2 stood for "only ventilation" and "ventilation and heating" modes in the all-air heating system performance.

Table 2. Details of the different scenarios considered for simulation

\begin{tabular}{|c|c|c|c|c|}
\hline Scenario & $\begin{array}{c}\text { Outdoor } \\
\text { temperature } \\
\left({ }^{\circ} \mathrm{C}\right)\end{array}$ & $\begin{array}{c}\text { Supply } \\
\text { temperature } \\
\left({ }^{\circ} \mathrm{C}\right)\end{array}$ & $\begin{array}{c}\text { Supply } \\
\text { airflow } \\
\text { rate }(1 / \mathrm{s})\end{array}$ & $A r$ \\
\hline S1 & -1.8 & 24 & 49.4 & $4.1 \times 10^{-3}$ \\
\hline S2 & -1.8 & 31 & 16 & $1.4 \times 10^{-3}$ \\
\hline S3 & -15 & 24 & 49.4 & $2.4 \times 10^{-3}$ \\
\hline S4 & -15 & 31 & 16 & $-8.2 \times 10^{-4}$ \\
\hline S5 & -1.8 & 24 & 16 & $5.1 \times 10^{-3}$ \\
\hline S6 & -1.8 & 31 & 49.4 & $1.1 \times 10^{-3}$ \\
\hline S7 & -15 & 24 & 16 & $2.9 \times 10^{-3}$ \\
\hline S8 & -15 & 31 & 49.4 & $-7.6 \times 10^{-4}$ \\
\hline
\end{tabular}

The system performance was analyzed in terms of both thermal comfort and temperature effectiveness for all the scenarios listed in Table 2. Furthermore, for implementing the thermal comfort indices $P P D$ and $P M V$, the required inputs were extracted from the Star$\mathrm{CCM}+$ and were then uploaded in a MATLAB code for the result post-processing.

\section{Results and discussion}

\subsection{Airflow distribution and temperature stratification}

Fig. 7 shows the velocity distribution near the supply diffuser for the eight scenarios.
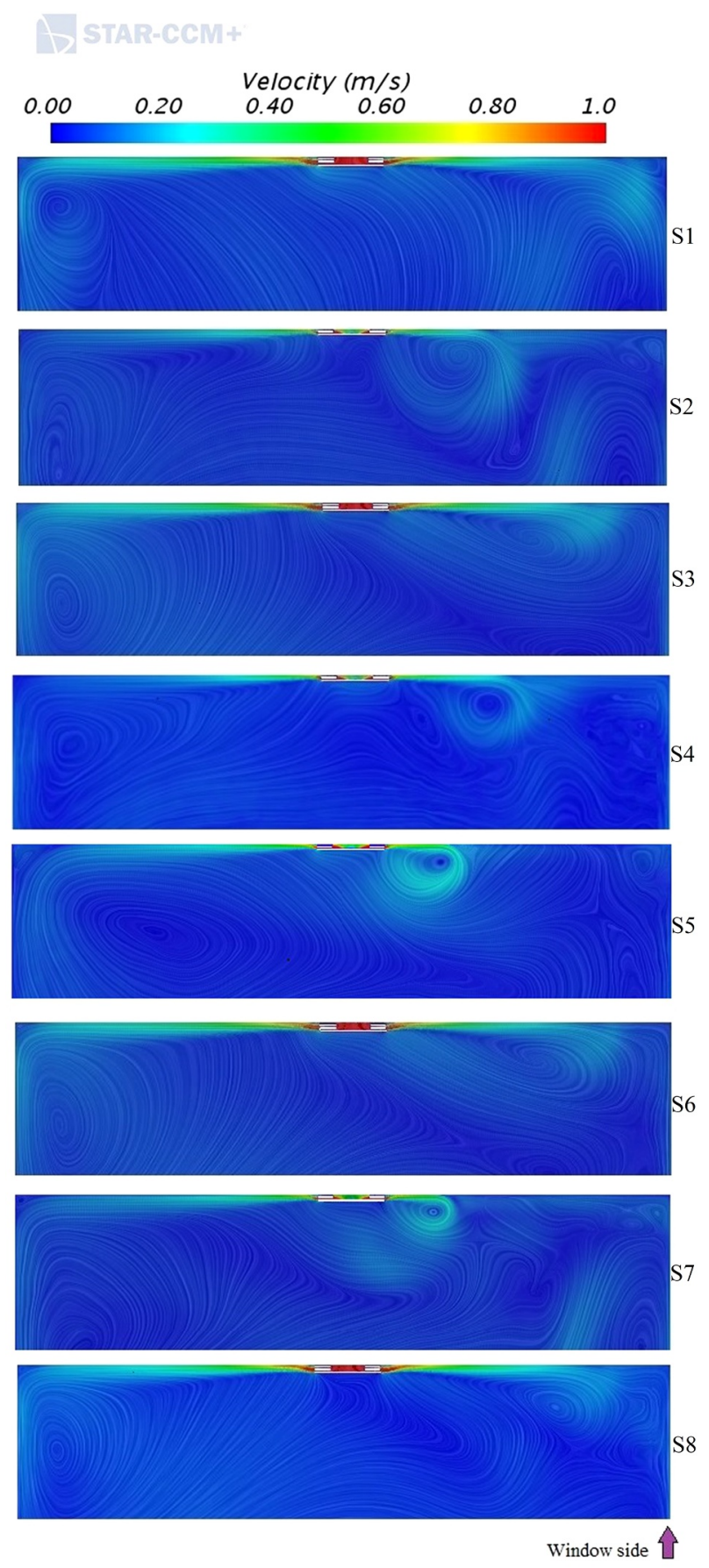

Fig. 7. Air velocity distribution behavior around the supply diffuser. The view plane section was taken at $\mathrm{y}=1.08 \mathrm{~m}$. 
It was observed that the active diffuser could almost create the same throw length towards the internal wall. However, different distribution patterns of the supply jet were generated towards the window side due to the different interaction behavior of the warm supply jet with the incoming cold current from the window at different supply and outdoor conditions, as shown Fig. 7. Moreover, the effect of supply airflow rate on the velocity distribution seemed to be more significant than other supply and outdoor parameters i.e. a strong circulating region was formed near the supply diffuser at lower airflow rate, see the light colors in Fig. 7 with higher velocity. Increasing the Archimedes number while the airflow rate was kept at higher airflow rate led to more homogeneous air velocity distribution near the supply area, see Fig. 7 for the scenarios S1, S3, S6.

Fig. 8 shows the vertical temperature profiles at different room heights. The active supply diffuser could avoid temperature stratification at different scenarios. In the cases where the Archimedes number was negative (S4 and S8) the temperature stratification was more pronounced. The maximum temperature stratification in the occupancy zone occurred in the scenario S4 with the temperature difference between head and ankle around $1.25^{\circ} \mathrm{C}$, which was still within the recommended range for even the first IAQ category according to the standard EN ISO 7730 [2]. Furthermore, a high air temperature experienced in the scenarios with the higher supply temperature showed that the heat gain could cover a great part of heating demand.

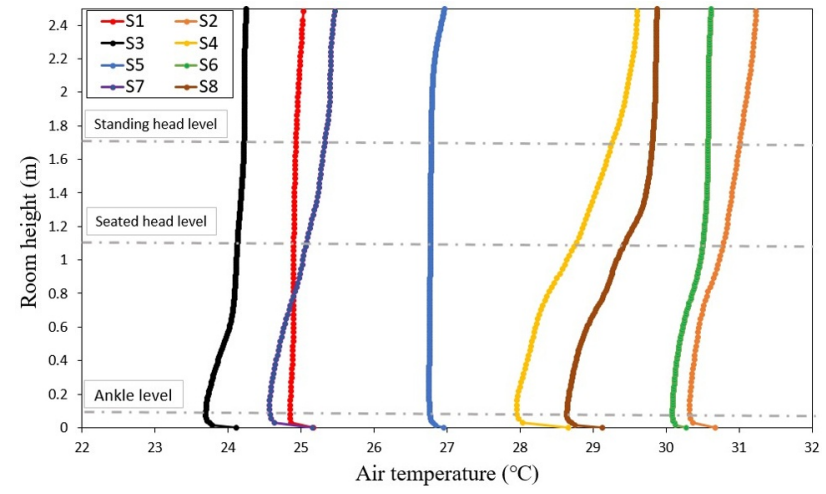

Fig. 8. Air vertical temperature variation vs room height

\subsection{Temperature effectiveness and thermal comfort analysis}

In order to evaluate the temperature effectiveness, the occupancy zone was defined based on the ASHRAE Standard 62 [16] as the region inside the space between $0.1 \mathrm{~m}$ and $1.8 \mathrm{~m}$ above the floor and more than $0.6 \mathrm{~m}$ from the side walls, as shown in Fig. 9.

Fig. 10 shows the temperature effectiveness for the different scenarios. The lowest temperature effectiveness around 38\% happened in the cases S4 and S8, where the system is operating in "ventilation and heating" mode and the Archimedes number is negative. This implied that the supply air was not properly distributed and mixed with the room air in the occupancy zone. The higher temperature stratification in these two scenarios, observed in Fig. 8, compared to other scenarios was also due to the low temperature effectiveness in these cases. The reason was the location of the exhaust valve on the ceiling, which led to short-circuiting of part of supply air. In addition, the high temperature effectiveness in the scenarios S2 and S6 could clearly indicate that such high supply temperature was unnecessary, as also observed in Fig. 8.

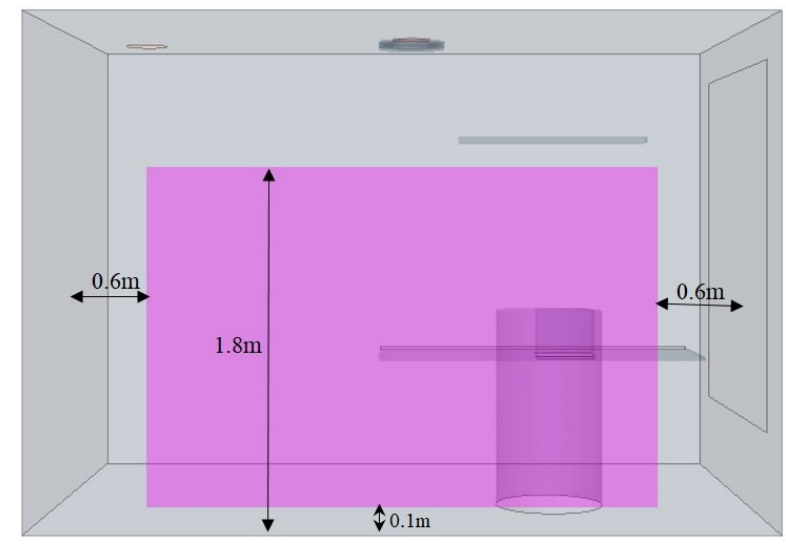

Fig. 9. Schematic of occupancy zone definition

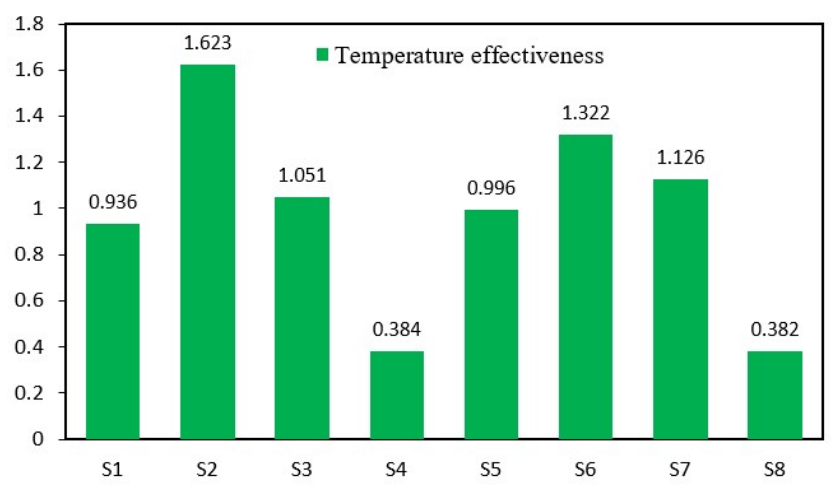

Fig. 10. Temperature effectiveness and Archimedes number variation in different scenarios

Fig. 11 shows the average $P M V$ in the occupancy zone. The dispersion of $P M V$ in each scenario was also reflected as error bars. It was calculated for the clothing level of $1 \mathrm{Clo}$, the metabolic rate of $1.2 \mathrm{Met}$, and the relative humidity of $50 \%$, as the common values used in calculations for office rooms. Among all the scenarios, only scenario $\mathrm{S} 3$ could meet the $P M V$ requirements according to the three comfort categories level and other cases seemed to be more functional in colder days. However, these cases were still beneficial for the buildings with higher heating demands. In addition, the scenarios S1 and S7 were close to the thermal comfort for the third comfort category $(-0.7<P M V<0.7)[14]$. 


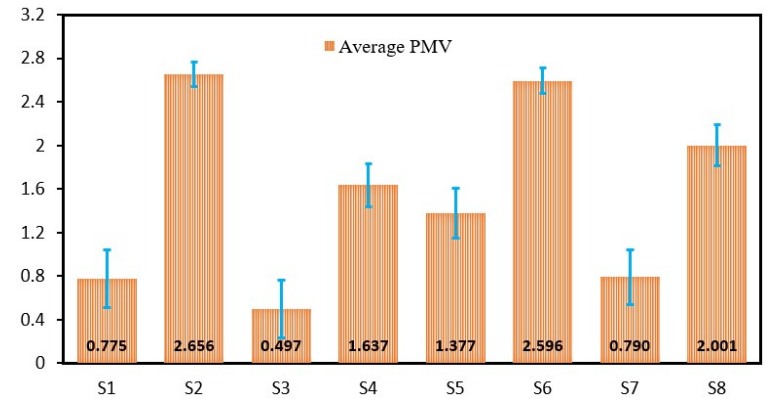

Fig. 11. Average $P M V$ variation in different scenarios

Due to large variation of $P M V$ values in scenario 3, the distribution $P P D$ was shown in different sections of the occupancy zone (Fig. 12). The discomfort area was mostly observed near the dummy with $P P D$ around 29\%, which was the reason of large variation in the percentage of dissatisfied range. However, the $P P D$ value in the occupancy zone varied in the dissatisfied range of 6 to 8 $\%$, which was in the thermal comfort requirements.

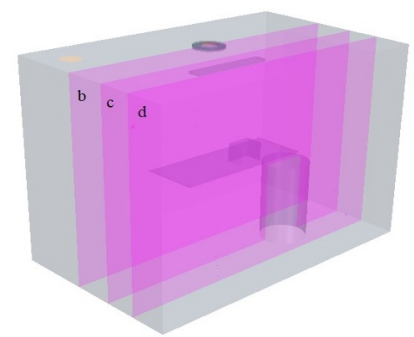

(a)

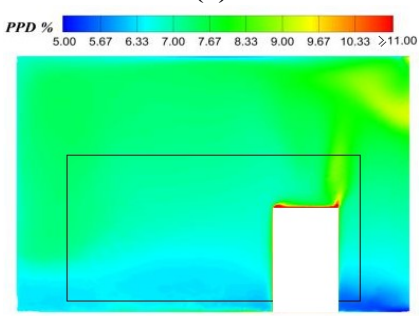

(c)

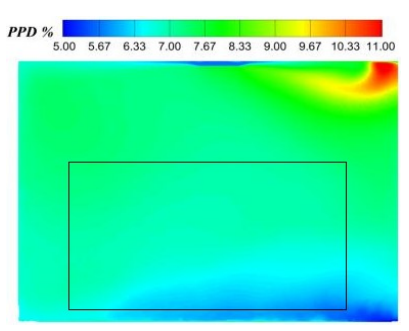

(b)

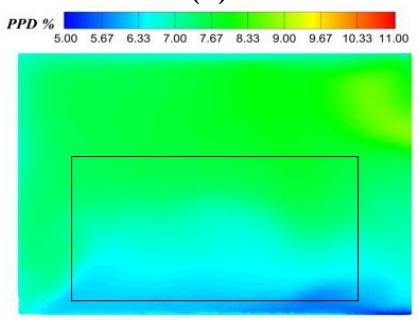

(d)
Fig. 12. $P P D$ spatial distribution at three different sections shown in (a). Black rectangle represents the occupancy zone

\section{Conclusion}

This paper dealt with the investigation of an air based heating system in a cell office equipped with active supply diffuser. The ventilation system performance was analyzed in terms of temperature stratification, ventilation effectiveness as well as thermal comfort indexes at different supply and outdoor conditions. The validation study revealed that the results obtained from simulations were in good agreement with the experimental data. The numerical results indicated that applying active supply diffuser could avoid the temperature stratification in different scenarios i.e. the maximum temperature stratification of $1.25{ }^{\circ} \mathrm{C}$ was observed, which was even within the recommended range for the category I thermal comfort. Nevertheless, different air distribution patterns were observed in the region where the interaction of supply jet and cold draught of the window surface occurred. Furthermore, the temperature level and the temperature effectiveness analysis showed that supplying the air with high temperature was inefficient in the current condition. The scenarios with negative Archimedes numbers showed the lowest temperature efficiency due to short-circuiting happened in these cases. The thermal comfort analysis indicated that the case with the supply temperature of 24 ${ }^{\circ} \mathrm{C}$, the airflow rate of $49.4 \mathrm{l} / \mathrm{s}$ at the outdoor temperature $-15{ }^{\circ} \mathrm{C}$ would result in a favorable average $P M V \sim 0.497$, according to the thermal comfort requirements, in the occupancy zone. However, a high dispersion of $P M V$ values appeared due to the high temperature of the heat source. Further studies should be performed with lower supply temperature at colder outdoor temperature to evaluate the performance of the system in critical conditions.

\section{References}

1. DIRECTIVE (EU) 2018/844 of the European parliament and of the council of 30 May 2018 amending Directive 2010/31/EU on the energy performance of buildings and Directive 2012/27/EU on energy efficiency (Text with EEA relevance), OJ EU (2018)

2. NS-3701, Standard Norge, Norway (2012)

3. K. Thunshelle, A. Cablé, M. Mysen, H.L. Hammer, 35th AIVC Conference, 4th TightVent Conference, 2nd venticool Conference., Poznan, Poland, (2014)

4. S. Liu, A. Novoselac, Build. Environ. 87, 215-223 (2015).

5. M. Krajčík, A. Simone, B.W. Olesen, Energy Build. 55, 94-101 (2012).

6. D. Risberg, M. Vesterlund, L. Westerlund, J. Dahl, Build. Environ. 89, 160-169 (2015)

7. A. Cablé, M. Mysen, K. Thunshelle, Indoor Air conference (2014)

8. TTC- Active supply diffuser. Avaiable from: https://www.lindinvent.com/products/airdiffusers/ttc/ (2018).

9. STAR CCM+ Users Manual (2017)

10.M.A.M. Brandan, Department of Mechanical Engineering, Massachusetts Institute of Technology (2012)

11. H. Shahid, D. Naylor, Energy Build. 37 (8), 836-843 (2005)

12.P.V. Nielsen, Dept. of Building Technology and Structural Engineering, Aalborg University, U9513 70 (1995).

13.D.W. Etheridge, M. Sandberg, Building ventilation: theory and measurement, John Wiley \& Sons Chichester, UK (1996)

14. NS-EN ISO 7730- Standard Norge, Norway (2006).

15.B.E. Launder, D.B. Spalding, Comput.Methods in Appl.Mech.Eng. 3 (2), 269-289 (1974)

16. ANSI/ASHRAE Standard 62.1., USA, Atlanta, GA (2010) 